\title{
Communication \\ Real World Outcomes and Hepatotoxicity of Infliximab in the Treatment of Steroid-Refractory Immune-Related Adverse Events
}

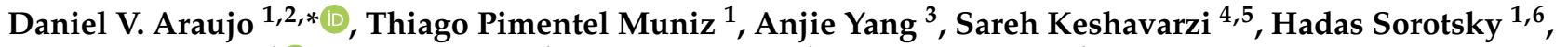 \\ Marcus O. Butler ${ }^{1}{ }^{1}$, Samuel Saibil ${ }^{1}$, Anna Spreafico ${ }^{1}$ and David Hogg ${ }^{1}$ \\ 1 Department of Medical Oncology and Hematology, Princess Margaret Cancer Center, \\ Toronto, ON M5G 1X6, Canada; thiago.muniz@uhn.ca (T.P.M.); hsorotsky@gmail.com (H.S.); \\ Marcus.Butler@uhn.ca (M.O.B.); sam.saibil@uhn.ca (S.S.); anna.spreafico@uhn.ca (A.S.); \\ david.hogg@uhn.ca (D.H.) \\ 2 Department of Medical Oncology, Hospital de Base, Sao Jose do Rio Preto 15090 000, Brazil \\ 3 Department of Pharmacy, University Health Network, Toronto, ON M5G 2M9, Canada; anjie.yang@uhn.ca \\ 4 Department of Biostatistics, Princess Margaret Cancer Center, Toronto, ON M5G 2M9, Canada; \\ Sareh.Keshavarzi@uhnresearch.ca \\ 5 Biostatistics Division, Dalla Lana School of Public Health, University of Toronto, \\ Toronto, ON M5T 3M7, Canada \\ 6 Cancer Center, Chaim Sheba Medical Center at Tel HaShomer, Ramat Gan 52621, Israel \\ * Correspondence: daniel.araujo@edu.famerp.br; Tel.:+55-17-3201-5096
}

Citation: Araujo, D.V.; Muniz, T.P.; Yang, A.; Keshavarzi, S.; Sorotsky, H.; Butler, M.O.; Saibil, S.; Spreafico, A.; Hogg, D. Real World Outcomes and Hepatotoxicity of Infliximab in the Treatment of Steroid-Refractory Immune-Related Adverse Events. Curr. Oncol. 2021, 28, 2173-2179. https://doi.org/10.3390/ curroncol28030201

Received: 15 May 2021

Accepted: 1 June 2021

Published: 11 June 2021

Publisher's Note: MDPI stays neutral with regard to jurisdictional claims in published maps and institutional affiliations.

\begin{abstract}
Background and aims: Current guidelines state that infliximab is contraindicated for the treatment of immune checkpoint inhibitor-related hepatitis (ir-hepatitis) due to the risk of inducing further liver damage. As this recommendation is largely based on the use of infliximab for rheumatologic diseases, we evaluated the efficacy and hepatotoxicity of infliximab in patients with steroid-refractory immune-related adverse events (irAEs). Methods: We retrospectively reviewed consecutive patients treated with infliximab for irAEs at Princess Margaret Cancer Centre. To assess hepatotoxicity, we compared the mean value of ALT, AST, and total bilirubin (BT) before and after infliximab treatment. We used logistic regression to assess factors associated with infliximab efficacy. Results: Between January 2010 and February 2019, 56 patients were identified. The median age of the patients was $63(27-84)$ years. Colitis was the most frequent toxicity $(66 \%)$, followed by pneumonitis $(11 \%)$. Infliximab was used to treat ir-hepatitis in one patient. The median number of infliximab doses was 1 (1-3) and led to toxicity resolution in 43 (76\%) patients. The mean ALT, AST, and BT levels before and after infliximab treatment were not statistically different. The patient treated for ir-hepatitis had a complete recovery, with no incremental liver toxicity. Conclusions: In this dose-limited setting, infliximab was effective in resolving irAEs and did not induce hepatotoxicity.
\end{abstract}

Keywords: infliximab; immunotherapy; toxicity; hepatotoxicity; immune-checkpoint inhibitors

\section{Introduction}

Immune checkpoint inhibitors (ICI), such as anti-programmed cell death 1 (antiPD1), anti-programmed cell death-ligand 1 (anti-PD-L1), and anti-cytotoxic T-Lymphocyte associated protein 4 (anti-CTLA-4) agents, act by disrupting inhibitory mechanisms of T-cell activation facilitating T-cell mediated cytotoxicity to cancer cells [1]. ICIs are administered either as monotherapy or a combination therapy across a variety of cancer types. Despite being safer than cytotoxic chemotherapy overall, ICIs frequently induce immune-related adverse events (irAEs) of varying severity. While most patients with severe irAEs achieve the complete resolution of their toxicities with the use of steroids, a smaller proportion are steroid-refractory and require additional immunosuppressive agents, including the anti-tumor necrosis factor alfa agent infliximab [2,3]. Infliximab is currently approved 
for the treatment of various non-cancerous autoimmune and inflammatory conditions such as inflammatory bowel diseases (IBD) [4] and psoriasis [5]. Although infliximab is recommended for most steroid-refractory irAEs, from relatively common conditions such as ir-colitis to other rarer irAEs [6], current guidelines recommend against its use for immunerelated hepatitis (ir-hepatitis) [2,3,7]. This tenet originates from reports of infliximabinduced hepatotoxicity in patients receiving infliximab as a treatment for rheumatologic disorders or IBD [8,9]. In those reports, most cases of hepatitis occurred following ongoing exposure to infliximab, in contrast to a single dose of infliximab that is commonly used in managing irAEs.

In this work, we examined the efficacy and hepatotoxicity of infliximab in a single institution series of cancer patients with steroid-refractory irAEs, with the aim to evaluate a possible revision of recommendations regarding the use of infliximab as a treatment for ir-hepatitis.

\section{Materials and Methods}

Following Research Ethics Board approval, we retrospectively identified consecutive patients treated with infliximab for irAEs deemed to be steroid refractory by the attending physician. Patients received infliximab at Princess Margaret Cancer Centre between January 2010 and February 2019. Data regarding tumor type, toxicity, ICI regimen at irAE onset (monotherapy vs. combination of 2 ICIs), toxicity resolution, tumor response to ICI, and survival were collected. Demographic characteristics were summarized as means, medians, and proportions. We assessed hepatotoxicity by comparing mean values of ALT, AST, and total bilirubin (BT) between $0-4$ weeks before and after infliximab therapy. When values were not available within 4 weeks, the nearest report was utilized. The Wilcoxon signed rank test was used to compare mean values. We used a logistic regression to investigate characteristics associated with irAE resolution. We performed multivariable analysis to adjust for potential confounders. Treatment efficacy assessed at the time of ICI toxicity onset was recorded as response rate (RR) per attending physician's assessment and categorized as complete response (CR), partial response (PR), stable disease (SD), or progressive disease (PD). Overall survival (OS) was calculated from the date of the first infliximab dose to date of death or last follow-up. All of the statistical analyses were performed in R (version 3.6.3, R Foundation for Statistical Computing, https:/ / www.R-project.org/ accessed on 8 March 2021), and a two-sided alpha level of 0.05 was used for determining statistical significance.

\section{Results}

We identified 56 patients who were included in this analysis. Table 1 summarizes patients' demographic characteristics. The median age was 63 years (27-84) and $38(68 \%)$ patients were male. The cancer types included melanoma in $35(62 \%)$, renal cell carcinoma (RCC) in $5(9 \%)$, and non-small cell lung cancer (NSCLC) in 4 (7\%) patients. At the time of the irAE onset, 25 (45\%) patients were receiving combination immunotherapy, of whom 19 $(76 \%)$ were an anti-PD-1 with an anti-CTLA-4 agent. Twenty-seven $(48 \%)$ patients were receiving monotherapy, of whom $13(48 \%)$ were on anti-PD1 and $11(40 \%)$ were being treated with ipilimumab (anti-CTLA-4). Another $4(7 \%)$ patients were being treated within blinded randomized clinical trials and had not been unblinded by a data cutoff. The most frequent toxicities treated with infliximab were colitis (37 cases; $66.1 \%$ ) and pneumonitis (6 cases; $10.7 \%)$. One patient $(1.7 \%)$ with ir-hepatitis received infliximab. 
Table 1. Characteristics of patients treated with infliximab. * Other cancer types are HNSCC, Uveal melanoma, esophageal-gastric adenocarcinoma, urothelial carcinoma, pancreas, breast. ** Participating in clinical trials randomizing to receive combination versus ICI monotherapy. *** Participating in clinical trials randomizing to receive either anti-CTLA-4 or anti-PD1. **** Other toxicities are erythema multiform dermatitis, arthritis, type 1 diabetes, Stevens-Johnson syndrome, rash, bullous pemphigoid, enteritis, and cytokine release syndrome. NSCLC = non-small cell lung cancer; RCC = renal cell carcinoma.

\begin{tabular}{|c|c|}
\hline $\mathbf{N}$ & 56 \\
\hline Age-mean (SD) & 62.9 (SD 12) \\
\hline \multicolumn{2}{|l|}{ Gender- $n(\%)$} \\
\hline Female & $18(32 \%)$ \\
\hline Male & $38(68 \%)$ \\
\hline \multicolumn{2}{|l|}{ Type of Cancer- $n(\%)$} \\
\hline Melanoma & $35(62 \%)$ \\
\hline NSCLC & $4(7 \%)$ \\
\hline RCC & $5(9 \%)$ \\
\hline Others * & $12(22 \%)$ \\
\hline \multicolumn{2}{|c|}{ Combination therapy at time of toxicity $-n(\%)$} \\
\hline No & $27(48 \%)$ \\
\hline Yes & $25(45 \%)$ \\
\hline Unknown ** & $4(7 \%)$ \\
\hline \multicolumn{2}{|l|}{ ICI monotherapy- $n(\%)$} \\
\hline Anti-CTLA4 & $11(40.8 \%)$ \\
\hline Anti-PD1 & $13(48.1 \%)$ \\
\hline Off ICI & $1(3.7 \%)$ \\
\hline Unknown $* * *$ & $2(7.4 \%)$ \\
\hline \multicolumn{2}{|l|}{ ICI Combination- $n(\%)$} \\
\hline Anti-CTLA4 + Anti-PD1 & $19(76 \%)$ \\
\hline Other & $6(24 \%)$ \\
\hline \multicolumn{2}{|l|}{ Type of Toxicity- $n(\%)$} \\
\hline Colitis & $37(66.1 \%)$ \\
\hline Hepatitis & $1(1.8 \%)$ \\
\hline Myocarditis & $2(3.6 \%)$ \\
\hline Pneumonitis & $6(10.7 \%)$ \\
\hline Others ${ }^{* * * *}$ & $10(17.8 \%)$ \\
\hline \multicolumn{2}{|c|}{ Multiple toxicities at Onset- $n(\%)$} \\
\hline No & $45(80 \%)$ \\
\hline Yes & $11(20 \%)$ \\
\hline \multicolumn{2}{|l|}{ Line of ICI treatment- $n(\%)$} \\
\hline Adjuvant & $5(9 \%)$ \\
\hline 1 st & $29(52 \%)$ \\
\hline 2nd & $13(23 \%)$ \\
\hline $3 r d$ & $6(11 \%)$ \\
\hline$\geq 4$ th & $3(5 \%)$ \\
\hline \multicolumn{2}{|c|}{ Best response to ICI that induced toxicity- $n(\%)$} \\
\hline $\mathrm{CR}$ & $4(7 \%)$ \\
\hline PR & $12(21 \%)$ \\
\hline SD & $13(23 \%)$ \\
\hline PD & $22(39 \%)$ \\
\hline $\mathrm{N} / \mathrm{A}$ & $5(9 \%)$ \\
\hline \multicolumn{2}{|l|}{ Outcome of toxicity $-n(\%)$} \\
\hline Not resolved & $13(24 \%)$ \\
\hline Resolved & $42(76 \%)$ \\
\hline Missing & 1 \\
\hline \multicolumn{2}{|l|}{ Resumed ICI-n $(\%)$} \\
\hline No & $46(82 \%)$ \\
\hline Yes & $10(18 \%)$ \\
\hline \multicolumn{2}{|c|}{ Recrudescence of Toxicity- $n(\%)$} \\
\hline No & $38(69 \%)$ \\
\hline Yes & $17(31 \%)$ \\
\hline
\end{tabular}


The median number of infliximab treatments was one (1-3). Infliximab treatment led to the resolution of irAEs in $43(76 \%)$ patients. Fourteen patients $(25 \%)$ required more than one dose of infliximab, which were separated by a median of 40.5 (12-867) days. After multivariable adjustment, colitis was more likely to respond to infliximab compared to all of the other irAEs combined $(\mathrm{OR}=6.73,95 \%$ CI $1.56-29, p=0.011)$. The tumor type (melanoma vs other cancers; $\mathrm{OR}=0.93,95 \% \mathrm{CI} 0.21-4.02, p=0.92$ ) and combination vs monotherapy ICI treatment ( $\mathrm{OR}=1.97,95 \%$ CI $0.48-8.11, p=0.64)$ did not affect the likelihood of an infliximab response (Table 2).

Table 2. Characteristics associated with the resolution of an irAE post-infliximab.

\begin{tabular}{|c|c|c|c|c|c|c|c|c|}
\hline \multirow{2}{*}{ Variable } & \multirow{2}{*}{ Resolved } & \multirow{2}{*}{ Not Resolved } & \multicolumn{3}{|c|}{ Univariable } & \multicolumn{3}{|c|}{ Multivariable } \\
\hline & & & OR & $95 \%$ CI & $p$ & OR & $95 \% \mathrm{CI}$ & $p$ \\
\hline \multicolumn{9}{|l|}{ Type of toxicity } \\
\hline Colitis & 32 & 5 & 5.12 & $1.36-19.24$ & 0.016 & 6.73 & $1.56-29.04$ & 0.011 \\
\hline Others & 10 & 8 & Reference & & & Reference & & \\
\hline \multicolumn{9}{|l|}{ Type of cancer } \\
\hline Melanoma & 7 & 28 & 1.71 & $0.48-6.07$ & 0.4 & 0.93 & $0.21-4.02$ & 0.92 \\
\hline Others & 6 & 14 & Reference & & & Reference & & \\
\hline Combo ICI at time of toxicity & & & & & 0.73 & & & 0.64 \\
\hline Yes & 5 & 20 & 1.68 & $0.47-6.07$ & & 1.97 & $0.48-8.11$ & \\
\hline No & 8 & 19 & Reference & $\mathrm{N} / \mathrm{A}$ & & Reference & & \\
\hline
\end{tabular}

There was no statistical difference between the mean values of AST, ALT, and BT before and after infliximab treatment (AST: 31.7 vs. $21.2 \mathrm{U} / \mathrm{L}, p=0.5$; ALT: 49 vs. $39.1 \mathrm{U} / \mathrm{L}$, $p=0.2$; and BT: 9.9 vs. $10.9 \mu \mathrm{mol} / \mathrm{L}, p=0.8$, respectively, Figure 1). A 27-year-old man with metastatic melanoma treated with the combination of an anti-CTLA-4 and an anti-PD1 agent developed steroid-refractory ir-hepatitis and was treated with one cycle of infliximab at the standard dose of $5 \mathrm{mg} / \mathrm{kg}$, achieving the normalization of transaminases. The patient did not experience recrudescence of hepatitis, further liver toxicity, or the occurrence of additional irAEs after infliximab treatment. Other than steroids, the patient did not receive any other immunosuppressive therapy before infliximab.

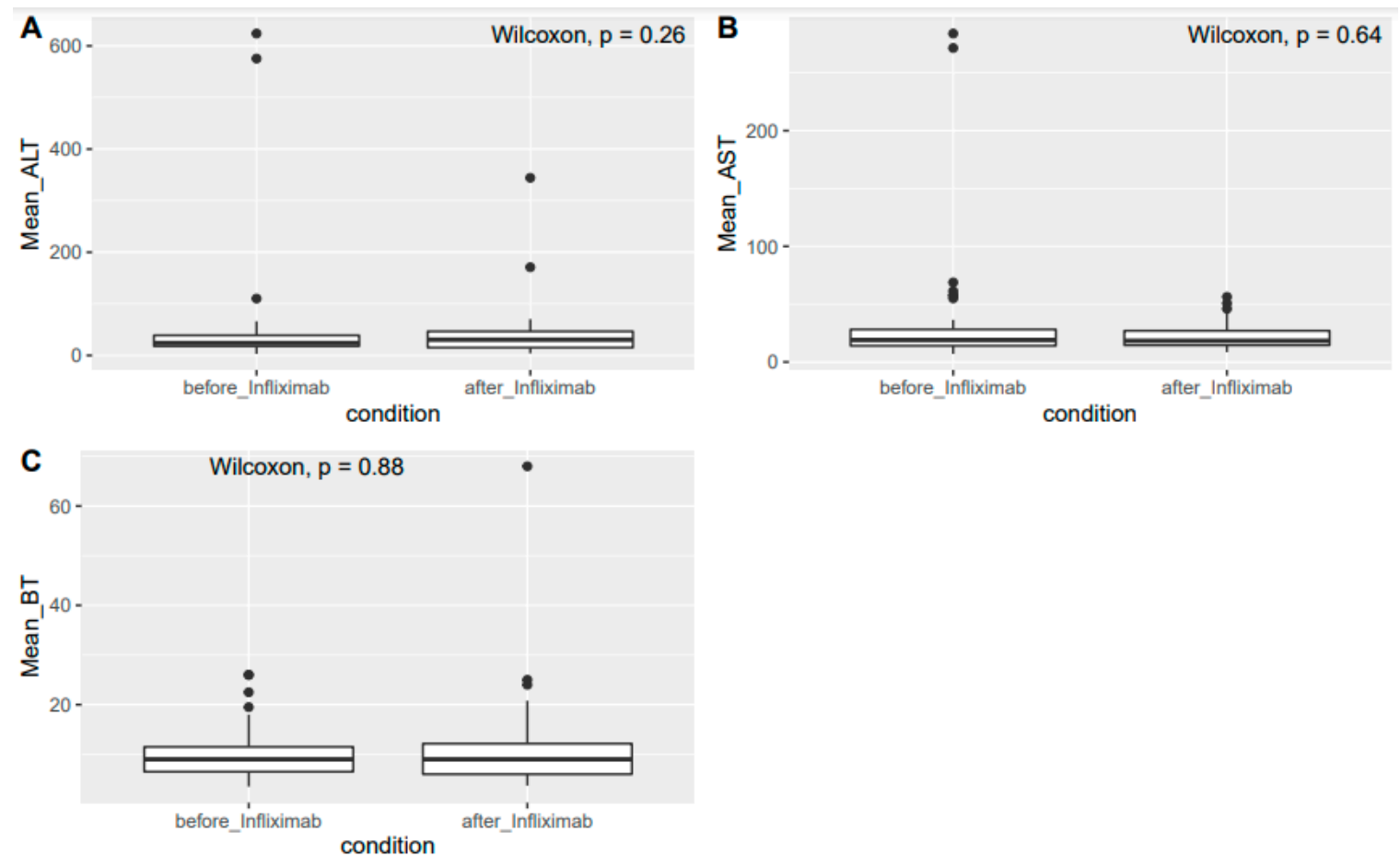

Figure 1. (A) Mean values of AST before and after infliximab. (B) Mean values of ALT before and after infliximab. (C) Mean values of TBILI before and after infliximab. 
In our cohort, the recurrence of an irAE (either the same or another irAE) occurred in $17(31 \%)$ patients, and $46(82 \%)$ patients did not resume ICI treatment post-infliximab treatment (Table 1). In regard to the efficacy of the ICI treatment being used at the time of toxicity, 50 patients were available for assessment. The best response was CR in 4 (7\%), PR in $12(22 \%)$, SD in $13(24 \%)$, and PD in $22(38 \%)$ patients. The median OS from the first infliximab dose was 13 months (95\% CI 7.3-19.3).

\section{Discussion}

In our study, infliximab was associated with the resolution of $76 \%$ of steroid-refractory irAEs in a real-world setting at an academic institution. The median number of infliximab infusions was one, which is in keeping with clinical experience [10]. Within this doselimited scenario (median number of doses was one), we did not observe significant changes between the mean AST, ALT, and BT values before and after infliximab treatment. The patient with steroid-refractory ir-hepatitis that was treated with infliximab responded well to treatment and his hepatitis resolved.

To the best of our knowledge, this is the first study that systematically examined the hepatotoxicity of infliximab in the treatment of steroid-refractory irAEs. Infliximab-induced hepatotoxicity has been described in patients with primary autoimmune conditions or IBD $[8,9]$. However, those patients were either treated on an ongoing basis and received multiple infliximab treatments over time (the median number of infliximab doses before hepatitis development was four) or were treated at a higher dose than the standard $5 \mathrm{mg} / \mathrm{kg}$ typically used in clinical practice for steroid-refractory irAEs [8,11,12]. Moreover, the usual treatment of infliximab-induced-hepatoxicity includes high-dose steroids, and most patients with ICI-induced irAEs are already receiving these drugs [12,13].

Infliximab has been previously used to treat autoimmune hepatitis refractory to azathioprine in a cohort of 11 patients leading to a decrease in transaminases, without inducing any additional liver toxicity [14]. In addition, a recent case report by Corrigan et al. described the use of infliximab to treat a patient with metastatic melanoma who developed ir-hepatitis refractory to both steroids and treatment with mycophenolate mofetil (MMF) [15]. After infliximab treatment, hepatitis was resolved, and no liver-toxicity was induced.

There is no published evidence that infliximab induces hepatotoxicity in a dose-limited setting in oncology patients, or that infliximab may aggravate steroid-refractory ir-hepatitis. On the contrary, the recommendation to avoid infliximab in patients with ir-hepatitis may compromise the optimal treatment of this irAE. The current immunosuppressants of choice for ir-hepatitis-MMF and azathioprine-require tapering, which may delay the re-initiation of ICI treatment for metastatic disease, thus potentially compromising the treatment's effectiveness. In contrast, infliximab is associated with a rapid kinetics of response and may allow for the earlier re-initiation of ICI treatment [10]. Nevertheless, re-initiation of ICI after an irAE carries a $28.8 \%$ chance of recurrence of the same irAE or may trigger the occurrence of a different one in $4.4 \%$ of cases [16].

In terms of ICI effectiveness, our data is consistent with a report by Burdett et al. in which a cohort of 19 patients required additional immunosuppression (refractory to steroids) for irAEs and an overall response rate to ICI of $35 \%$ and a median OS of 9.4 months was found [17]. Overall, these results are inferior to those reported in the pivotal trials of ICI for melanoma [18], NSCLC [19,20], and RCC [21,22]. The heterogeneity of our cohort, both in respect to different tumor types and different stages, as well as the small number of patients included, may explain some of the observed discrepancies. While the occurrence of irAEs in general has been found to correlate with increased survival, most patients included in these analyses developed mild toxicities [23]. The potential detrimental effects of long-term/stronger immunosuppression, including infliximab, in patients who developed ICI-related toxicities are yet to be determined and should be evaluated in larger datasets [24]. 
The limitations of this work include its retrospective nature, the absence of steroidrefractory disease confirmation in all patients (e.g., colonoscopy and biopsy in colitis, or bronchoscopy and BAL in pneumonitis), and the low rate of ir-hepatitis treated with infliximab (one patient). Nonetheless, to date, this is the first study systematically assessing the hepatoxicity of infliximab in the treatment of irAEs and the largest cohort assessing outcomes of patients treated with infliximab in the setting of ICI-induced steroidrefractory irAEs.

\section{Conclusions}

In our cohort, infliximab was associated with a high rate of resolution of irAEs and was not associated with hepatoxicity development. A patient with ir-hepatitis that was treated with infliximab had his toxicity resolved with no recurrence. Infliximab may be an option for the treatment of ir-hepatitis and should be tested in a randomized trial to determine its efficacy and safety in the dose-limited context of ICI-related toxicity.

Author Contributions: Conceptualization, D.V.A., H.S. and D.H.; methodology, D.V.A.; formal analysis, D.V.A. and S.K.; investigation, D.V.A., T.P.M., A.Y. and H.S.; resources, M.O.B., S.S., A.S. and D.H.; data curation, D.V.A. and T.P.M.; writing—original draft preparation, D.V.A. and T.P.M.; writing—-review and editing, all authors.; visualization, all authors.; supervision, A.S. and D.H.; All authors have read and agreed to the published version of the manuscript.

Funding: This work was partially funded by The David Cornfield Melanoma Award (D.V.A.).

Institutional Review Board Statement: The study was conducted according to the guidelines of the Declaration of Helsinki, and approved by the Institutional Review Board of University Health Network (protocol code: 19-5413 and date of approval: 15 May 2019).

Informed Consent Statement: Patient consent was waived as this is a de-identified retrospective study with minimal risks to participants.

Data Availability Statement: The datasets used and/or analysed during the current study are available from the corresponding author on reasonable request.

Acknowledgments: D.V.A., T.P.M. and H.S. have received fellowship funding from Alamos Gold Inc.

Conflicts of Interest: D.V.A. has received honoraria from GlaxoSmithKline; M.O.B. consults for Bristol-Myers Squibb, Novartis, Merck, GlaxoSmithKline, EMD Serono, Sanofi, and Immunocore, and has received grant/research support from (clinical trials) Merck and Takara Bio. S.S. has received personal fees from Janssen and Novartis outside the submitted work. A.S. has participated on the advisory board of Novartis, BMS, Merck, and Oncorus; received travel accommodations expenses and accommodations from Merck, BMS, Idera, Bayer, Jansen Oncology, and Roche; received honoraria from Jansen Oncology; and received research funding from BMS, Novartis, Merck, Symphogen, AstraZeneca/MedImmune, Bayer, Surface Oncology, Jansen Oncology, Northern Biologics, Replimune, Roche, Alkermes, and Array Biopharma. D.H. has participated on the advisory board of BMS, Merck Serono, Merck, Novartis, and Roche, and has received research funding from BMS and Merck Serono. T.P.M., A.Y., H.S. and S.K. do not have conflicts to disclose.

\section{References}

1. Pennock, G.K.; Chow, L.Q.M. The Evolving Role of Immune Checkpoint Inhibitors in Cancer Treatment. Oncologist 2015, 20, 812-822. [CrossRef]

2. Brahmer, J.R.; Lacchetti, C.; Schneider, B.J.; Atkins, M.B.; Brassil, K.J.; Caterino, J.M.; Chau, I.; Ernstoff, M.S.; Gardner, J.M.; Ginex, P.; et al. Management of Immune-Related Adverse Events in Patients Treated With Immune Checkpoint Inhibitor Therapy: American Society of Clinical Oncology Clinical Practice Guideline. J. Clin. Oncol. 2018, 36, 1714-1768. [CrossRef]

3. Haanen, J.B.A.G.; Carbonnel, F.; Robert, C.; Kerr, K.M.; Peters, S.; Larkin, J.; Jordan, K. Management of toxicities from immunotherapy: ESMO Clinical Practice Guidelines for diagnosis, treatment and follow-upt. Ann. Oncol. 2017, 28, iv119-iv142. [CrossRef] [PubMed]

4. Roberti, R.; Iannone, L.F.; Palleria, C.; De Sarro, C.; Spagnuolo, R.; Barbieri, M.A.; Vero, A.; Manti, A.; Pisana, V.; Fries, W.; et al. Safety profiles of biologic agents for inflammatory bowel diseases: A prospective pharmacovigilance study in Southern Italy. Curr. Med. Res. Opin. 2020, 36, 1457-1463. [CrossRef] [PubMed] 
5. Iannone, L.F.; Bennardo, L.; Palleria, C.; Roberti, R.; De Sarro, C.; Naturale, M.D.; Dastoli, S.; Donato, L.; Manti, A.; Valenti, G.; et al. Safety profile of biologic drugs for psoriasis in clinical practice: An Italian prospective pharmacovigilance study. PLoS ONE 2020, 15, e0241575. [CrossRef] [PubMed]

6. Indini, A.; Sessa, M.; Merelli, B.; Foresti, C.; Mandalà, M. A case of severe pharyngeal-cervical-brachial syndrome induced by nivolumab and responding to infliximab therapy. Eur. J. Cancer 2020, 129, 1-3. [CrossRef] [PubMed]

7. Reynolds, K.; Thomas, M.; Dougan, M. Diagnosis and Management of Hepatitis in Patients on Checkpoint Blockade. Oncologist 2018, 23, 991-997. [CrossRef] [PubMed]

8. Vollmer, O.; Felten, R.; Mertz, P.; Lebrun-Vignes, B.; Salem, J.-E.; Arnaud, L. Characterization of auto-immune hepatitis associated with the use of anti-TNF $\alpha$ agents: An analysis of 389 cases in VigiBase. Autoimmun. Rev. 2020, 19, 102460. [CrossRef]

9. Worland, T.; Chin, K.L.; van Langenberg, D.; Garg, M.; Nicoll, A. Retrospective study of idiosyncratic drug-induced liver injury from infliximab in an inflammatory bowel disease cohort: The IDLE study. Ann. Gastroenterol. 2020, 33, 162-169. [CrossRef]

10. Johnson, D.H.; Zobniw, C.M.; Trinh, V.A.; Ma, J.; Bassett, R.L.; Abdel-Wahab, N.; Anderson, J.; Davis, J.E.; Joseph, J.; Uemura, M.; et al. Infliximab associated with faster symptom resolution compared with corticosteroids alone for the management of immune-related enterocolitis. J. Immunother. Ther. Cancer 2018, 6, 103. [CrossRef]

11. Sokolove, J.; Strand, V.; Greenberg, J.D.; Curtis, J.R.; Kavanaugh, A.; Kremer, J.M.; Anofrei, A.; Reed, G.; Calabrese, L.; Hooper, M.; et al. Risk of elevated liver enzymes associated with TNF inhibitor utilisation in patients with rheumatoid arthritis. Ann. Rheum. Dis. 2010, 69, 1612. [CrossRef] [PubMed]

12. Ghabril, M.; Bonkovsky, H.L.; Kum, C.; Davern, T.; Hayashi, P.H.; Kleiner, D.E.; Serrano, J.; Rochon, J.; Fontana, R.J.; Bonacini, M.; et al. Liver Injury From Tumor Necrosis Factor- $\alpha$ Antagonists: Analysis of Thirty-four Cases. Clin. Gastroenterol. Hepatol. 2013, 11, 558-564.e553. [CrossRef] [PubMed]

13. Mancini, S.; Amorotti, E.; Vecchio, S.; Ponz de Leon, M.; Roncucci, L. Infliximab-related hepatitis: Discussion of a case and review of the literature. Intern. Emerg. Med. 2010, 5, 193-200. [CrossRef] [PubMed]

14. Weiler-Normann, C.; Schramm, C.; Quaas, A.; Wiegard, C.; Glaubke, C.; Pannicke, N.; Möller, S.; Lohse, A.W. Infliximab as a rescue treatment in difficult-to-treat autoimmune hepatitis. J. Hepatol. 2013, 58, 529-534. [CrossRef]

15. Corrigan, M.; Haydon, G.; Thompson, F.; Rajoriya, N.; Peplow, C.L.; Hubscher, S.G.; Steven, N.; Hirschfield, G.M.; Armstrong, M.J. Infliximab for the treatment of refractory immune-related hepatitis secondary to checkpoint inhibitors: A case report. JHEP Rep. 2019, 1, 66-69. [CrossRef] [PubMed]

16. Dolladille, C.; Ederhy, S.; Sassier, M.; Cautela, J.; Thuny, F.; Cohen, A.A.; Fedrizzi, S.; Chrétien, B.; DA Silva, A.; Plane, A.-F.; et al. Immune Checkpoint Inhibitor Rechallenge after Immune-Related Adverse Events in Patients With Cancer. JAMA Oncol. 2020, 6, 865-871. [CrossRef]

17. Burdett, N.; Hsu, K.; Xiong, L.; Tapia-Rico, G.; Beckmann, K.; Karapetis, C.; Brown, M.P. Cancer outcomes in patients requiring immunosuppression in addition to corticosteroids for immune-related adverse events after immune checkpoint inhibitor therapy. Asia-Pac. J. Clin. Oncol. 2020, 16, e139-e145. [CrossRef]

18. Larkin, J.; Chiarion-Sileni, V.; Gonzalez, R.; Grob, J.-J.; Rutkowski, P.; Lao, C.D.; Cowey, C.L.; Schadendorf, D.; Wagstaff, J.; Dummer, R.; et al. Five-Year Survival with Combined Nivolumab and Ipilimumab in Advanced Melanoma. N. Engl. J. Med. 2019, 381, 1535-1546. [CrossRef]

19. Reck, M.; Rodríguez-Abreu, D.; Robinson, A.G.; Hui, R.; Csőszi, T.; Fülöp, A.; Gottfried, M.; Peled, N.; Tafreshi, A.; Cuffe, S.; et al. Pembrolizumab versus Chemotherapy for PD-L1-Positive Non-Small-Cell Lung Cancer. N. Engl. J. Med. 2016, 375, 1823-1833. [CrossRef]

20. Gandhi, L.; Rodríguez-Abreu, D.; Gadgeel, S.; Esteban, E.; Felip, E.; De Angelis, F.; Domine, M.; Clingan, P.; Hochmair, M.J.; Powell, S.F.; et al. Pembrolizumab plus Chemotherapy in Metastatic Non-Small-Cell Lung Cancer. N. Engl. J. Med. 2018, 378, 2078-2092. [CrossRef]

21. Motzer, R.J.; Escudier, B.; McDermott, D.F.; George, S.; Hammers, H.J.; Srinivas, S.; Tykodi, S.S.; Sosman, J.A.; Procopio, G.; Plimack, E.R.; et al. Nivolumab versus Everolimus in Advanced Renal-Cell Carcinoma. N. Engl. J. Med. 2015, 373, 1803-1813. [CrossRef] [PubMed]

22. Motzer, R.J.; Tannir, N.M.; McDermott, D.F.; Frontera, O.A.; Melichar, B.; Choueiri, T.K.; Plimack, E.R.; Barthélémy, P.; Porta, C.; George, S.; et al. Nivolumab plus Ipilimumab versus Sunitinib in Advanced Renal-Cell Carcinoma. N. Engl. J. Med. 2018, 378, 1277-1290. [CrossRef] [PubMed]

23. Shankar, B.; Zhang, J.; Naqash, A.R.; Forde, P.M.; Feliciano, J.L.; Marrone, K.A.; Ettinger, D.S.; Hann, C.L.; Brahmer, J.R.; Ricciuti, B.; et al. Multisystem Immune-Related Adverse Events Associated With Immune Checkpoint Inhibitors for Treatment of Non-Small Cell Lung Cancer. JAMA Oncol. 2020, 6, 1952-1956. [CrossRef] [PubMed]

24. Das, S.; Johnson, D.B. Immune-related adverse events and anti-tumor efficacy of immune checkpoint inhibitors. J. Immunother. Ther. Cancer 2019, 7, 306. [CrossRef] 